\title{
Multifunctional Magnetite Nanoparticlesfor Drug Delivery: Preparation, Characterisation, Antibacterial Properties and Drug Release Kinetics
}

\author{
Mostafa Mabrouk ${ }^{1,3,4}$, Rasha M. Abd EI-Wahab², Hanan H. Beherei', Mohamed M. \\ Selim², Diganta B. Das ${ }^{3,4}$ \\ ${ }^{1}$ Refractories, Ceramics and Building Materials Department, National Research Centre (NRC), \\ 33El Bohouth St (former EL Tahrir St), Dokki, Giza, P.O.12622, Egypt \\ ${ }^{2}$ Physical Chemistry Department, National Research Centre, NRC, 33 EL Bohouth St., Dokki, \\ P. O. 12622, Giza, Egypt \\ ${ }^{3}$ Department of Chemical Engineering, Loughborough University, Loughborough LE113TU, \\ Leicestershire, UK
}

Revised paper submitted for consideration and publication in

International Journal of Pharmaceutics

11 July 2020

${ }^{4}$ To whom correspondence could be addressed

(e-mails: mostafamabrouk.nrc@gmail.com; d.b.das@lboro.ac.uk) 


\section{Abstract}

Multifunctional nanoparticles (NPs) with magnetic (M) and antibacterial properties were prepared for drug delivery purposes by a method involving co-precipitation synthesis. Partial and complete substitutions of ferrous ions $\left(\mathrm{Fe}^{2+}\right)$ by copper ions $\left(\mathrm{Cu}^{2+}\right)$ were carried out for the preparation of the magnetite NPs, which are designated as $\mathrm{Cu}_{0.5} \mathrm{M}$ and $\mathrm{CuM}$, respectively, in this work. In addition, chitosan and ciprofloxacin were hybridized with the NPs from the previous step to achieve multifunctional properties. XRD, TEM, SEM/EDAX, VSM and FTIR were subsequently employed to characterize various properties of the prepared NPs, namely, crystallinity, nanostructure (size), particle morphology, elemental mapping, magnetic strength and chemical composition. Antibacterial properties of the NPs were tested against Bacillus cereus (Gram-positive bacteria), Escherichia coli (Gram-negative bacteria) and Candida albicans (yeast). Efficiency of the ciprofloxacin release was also studied for the drug-loaded NPs. It is demonstrated that the obtained NPs possess mixed phases with crystalline structures that are affected by the degree of $\mathrm{Cu}$ ion substitution (5-10nm (M), 2.5-3.5nm $\left(\mathrm{Cu}_{0.5} \mathrm{M}\right)$ and 11-16nm (CuM)). Saturation magnetization values of the NPs were recorded as 38.7, 3.5 and 1.3 emu/g, respectively. It was also found that the introduction of $\mathrm{Cu}$ ions in the NP samples improved the significance of their antibacterial activity, especially against Escherichia coli. Chitosan and ciprofloxacin were found to have stronger effects against Bacillus cereus and Escherichia coli and lesser effects against Candida albicans. However, the samples containing chitosan, ciprofloxacin and the higher $\mathrm{Cu}$ ion concentration exhibited strong influence against Candida albicans. During a study period of 30days, the amounts of released drug from the tested NPs were 85, 26 and $20 \%$ of the originally loaded amount, respectively. Owing to the findings in this paper, the developed NPs are considered to have good potential for drug delivery applications and to study them further such as in pre-clinical studies.

Keywords: Nanoparticles; magnetite; copper-substitution; drug delivery vehicles; antibacterial activity; drug release kinetics.

\section{Introduction}

Nanoparticles (NPs) have been successfully implemented for disease diagnosis, in vivo molecular imaging and improved efficacy for therapeutic delivery (Suk et al., 2016, Mahdavinia et al., 2019, Piñeiro et al., 2020). The applications of NPs are particularly advantageous in achieving these goals due to their small particle size, large surface area, ability for in vivo drug delivery and, tunable electronic, optical and magnetic properties (Yang et al., 2012). Consequently, a plethora of NPs with different characteristics have been prepared using different materials which have prompted a growing interest for their use in biomedical engineering and imaging (e.g., Yu et al., 2012, Mahdavinia et al., 2019). Due to the bio-compatible and superparamagnetic nature, magnetic nanoparticles (MNPs) are emerging as excellent candidates for biomedical applications 
such as magnetic targeting, real-time monitoring of diseases using magnetic resonance imaging (MRI) (Yang et al., 2012) and, hyperthermia treatment of cancer (Yu et al., 2012, Arora et al., 2017, Spirou et al., 2018, Hosu et al., 2019). Modified MNPs have also been observed to inhibit microbial development (Rodrigues et al., 2019). According to previous researchers, a possible antibacterial activity mechanism of metallic NPs action is the electromagnetic attraction between the NPs and the microorganisms, due to positively charged NPs and negatively charged microbes (Spulber et al., 2018). Several antimicrobial agents based on transition metals (d-block) have been investigated for antimicrobial agents (e.g., Cr, V, Co, Ti, Cu, Ni, Fe, Zn, Ag, W, Cd, Hg, Au) (Slavin et al., 2017). In particular, ferrite $\left(\mathrm{Fe}_{3} \mathrm{O}_{4}\right)$ NP-based structures are of importance in targeted drug delivery (Turner et al., 2017). The unique properties of the NPs, viz., large saturation magnetization, superparamagnetic nature, chemical inertness, increased surface-to-volume ratio, morphology control through synthesis and biocompatibility of metal-ferrite nanocomposites/NPs have led towards a great motivation for developing new $\mathrm{Fe}_{3} \mathrm{O}_{4}$ NPs for drug delivery (Piñeiro et al., 2020).

MNPs are prone to aggregation due to the presence of magnetic dipole-dipole interactions or Van der Waals forces which lead to their detection and clearance from the human body by the mononuclear phagocytic system (MPS2) before they can reach their target sites, thus, limiting their biomedical applications (Urquijo et al., 2011, Yu et al., 2012, Aisida et al., 2020). Suk et al. (2016) have utilized magnetite NPs coated with various polymers to prevent their oxidation and aggregation with a view to introduce a steric or electrostatic repulsion between them. MNPs with a biopolymer coating allow for a sequestration of drug molecules which improve the biocompatibility of the NPs while allowing the attachment of the targeting moieties. A common natural polymer utilized as a biomaterial and in drug delivery vehicles is chitosan. Chitosan consideration in biomedicine field is based on the existence of its amine groups. Also, it can be delivered into humans with relatively higher concentrations and its biosafety is maintained as proven through rat models (Chiu et al., 2020). It can be easily crosslinked and modified into gels which can carry biologically-active molecules. Accordingly, chitosan was utilized combined with MNPS for medication selective delivery (Pham et al., 2016). This innovation permits onsite conveyance as the movement of covered MNPs loaded with a drug molecule is adjusted by external magnetic field.

Additionally, several forms of chitosan have been utilized in different in vitro and in vivo studies proving their broad antimicrobial activities against various microorganisms that include yeasts, fungi, bacteria and algae. For example, several applications for chitosan were explored for their positive influence in bone and skin regenerations (El-Sayed et al., 2020; Liu et al., 2018). It is also worthy to highlight that the inclusion of antibiotics in implantable or injectable systems must be ensured to avoid bacterial infections that might occur during the drug-loaded NP delivery process. 
Keeping these in mind, we have selected ciprofloxacin as the drug to load on the NPs. This is because ciprofloxacin is efficient in controlling different types of infections and inflammations (Korzeniowska et al., 2020). However, the unique features of chitosan as mentioned above, its magnetic nanoparticulate form especially when doped with transition metals (Spulber, et al., 2018, Turner, 2017) and antibacterial properties make a hybridization between a multifunctional material with different properties attractive. In this work, incorporating ciprofloxacin in the chitosan/MNPs matrix was the point of interest for antibacterial and drug release study where the key parameter affecting these was the copper $(\mathrm{Cu})$ ion concentration. $\mathrm{Cu}$ was chosen as a model for transition metal owing to its noticeable bacterial activity. In addition, $\mathrm{Cu}$ has good chelation properties with chitosan.

Different methods have been used for preparing NPs, e.g., combustion-based synthesis (Abd ElWahab et al., 2014), hydrothermal (Justin et al., 2010), sol-gel (Srivastava et al., 2009), solid-state reaction (Wang et al., 2002), electrochemistry (Dierstein et al., 2001), microemulsion (Han et al., 2004), hard template (Wang and Xia, 2006), spray pyrolysis (Wang et al., 2004), reverse micellar formation (Ahmad et al., 2006) and precipitation process (Karthik et al., 2011). Most of these methods have drawbacks for NPs preparation, such as elevated costs, high pressures and temperatures requirements, low yields, generation of large amount of toxic and expensive solvents hampering their implementation on an industrial scale (Cruz et al., 2018). Considering these, coprecipitation synthesis was selected in this work to prepare NPs as they are facile, inexpensive and quick, and it's efficient in up scaling NP production methods. It concedes nanomaterials with low amounts of impurities through an eco-accommodating course, without requiring unsafe solvents or preparation under high temperature or pressure (Cruz et al., 2018). In addition, it is expected that the existence of another metal other than the iron in the magnetite structure will induce several alterations for the final properties of the developed MNPs such as physico-chemical features, particle diameter, morphology and magnetization performance as well. Antibacterial activity, drug loading efficiency and release kinetics are also expected to be influenced by the same factors along with chitosan/ciprofloxacin hybridizations. Therefore, this research is motivated to explain in detail the expected alterations by these factors on the developed MNPs.

At the beginning of the paper, we describe the fabrication and depiction of magnetite NPs (M), partial substitution of ferrous ions by $\mathrm{Cu}$ ion $\left(\mathrm{Cu}_{0.5} \mathrm{M}\right)$, and, a complete substitution of ferrous ions by $\mathrm{Cu}$ ions(CuM). Also, the preparation and characterization of the previous samples coated with chitosan $\mathrm{ChM}$ (sample $\mathrm{M}$ with chitosan), $\mathrm{ChCu}_{0.5} \mathrm{M}$ (sample $\mathrm{Cu}_{0.5} \mathrm{M}$ with chitosan), ChCuM (sample CuM with chitosan) were investigated. Introducing the antibiotic ciprofloxacin to the NPs samples containing chitosan, CipChM (ChM with ciprofloxacin), $\mathrm{CipChCu}_{0.5} \mathrm{M}\left(\mathrm{ChCu}_{0.5} \mathrm{M}\right.$ with ciprofloxacin), CipChCuM (ChCuM with ciprofloxacin) was also conducted. Finally, we examine the antibacterial 
activities of all the prepared samples and, study the drug release kinetics and the release efficiency from the drug loaded NPs.

\section{Materials and methods}

\subsection{Chemicals, reagents and materials}

$\mathrm{Fe}\left(\mathrm{NO}_{3}\right) 3.9 \mathrm{H}_{2} \mathrm{O}$ (Loba Chemie), $\mathrm{FeSO}_{4} .7 \mathrm{H}_{2} \mathrm{O}$ (S D Fine-Chem Limited, SDFCL), $\mathrm{Cu}\left(\mathrm{NO}_{3}\right)_{2} 3 \mathrm{H}_{2} \mathrm{O}$ (Laboratory Rasayan Co.), $\mathrm{NaOH}$ pellets (SDFCL), chitosan (MW=100,000-300,000Daltons; Acros Organics, Germany), ciprofloxacin 98.0\% (HPLC grade chemical; Fluka, Neu-Ulm, Germany; MW $=331.34 \mathrm{~g} / \mathrm{mol})$. All microorganisms used in this work were obtained from the non-profit organization American Type Culture Collection (ATCC, Rockville MD, USA) and Northern Utilization Research and Development Division, United State Department of Agriculture, Peoria, Illinois, USA (NRRL). The bacteria used in this work were Gram-positive bacterial strains (Bacillus cereus ATCC-6629), Gram-negative bacterial strains (Escherichia coli ATCC-51659) and yeast (Candida albicans ATCC-10231). The bacterial strains were revived for bioassay by sub-culturing in fresh nutrient broth medium for 24 hours before the tests. The yeasts were cultured on potato dextrose agar (PDA) for 7 days at $28^{\circ} \mathrm{C}$ before the antibacterial tests were carried out.

\subsection{Preparation of magnetite and $\mathrm{Cu}$ substituted solutions}

$\mathrm{Fe}_{3} \mathrm{O}_{4} \mathrm{NPs}(\mathrm{M})$ were prepared utilizing the precursor salts ferrous sulphate and ferric nitrate at 1:2 molar ratio as follows. Iron (II) sulphate and iron (III) nitrate solutions were prepared by dissolving $14 \mathrm{gm}$ and $40.4 \mathrm{gm}$ of the salts, respectively, in $1 \mathrm{~L}$ of distilled water supplemented with nitrogen gas purging. Nitrogen gas was selected for purging due to its inertness to the solutions and its easy availability. After complete dissolution (transparent solutions) of the salts, the two solutions were mixed. When the mixture temperature reaches $\approx 70^{\circ} \mathrm{C}, 5 \% \mathrm{NaOH}$ solution was titrated onto the beaker containing the mixture until complete precipitation of the black precipitate of $\mathrm{Fe}_{3} \mathrm{O}_{4}$ is achieved(the complete precipitation is indicated by testing the filtrate solution against drops of $\mathrm{NaOH}$ ). The prepared sample was then washed with distilled water many times. The partial $\mathrm{Cu}$ substituted sample, $\mathrm{Cu}_{0.5} \mathrm{M}$, was prepared by dissolving $6.04 \mathrm{gm}$ of $\mathrm{Cu}$ nitrate in $500 \mathrm{ml}$ distilled water under a nitrogen gas atmosphere and $7 \mathrm{gm}$ of ferrous sulphate in $500 \mathrm{ml}$ distilled water under a nitrogen gas atmosphere. After that the mixture was added to the same concentration and volume of iron (III) nitrate solution as done for the $\mathrm{M}$ preparation. Then, it was prepared under the same conditions as the previous sample. In the absence of ferrous ions, they are substituted by $\mathrm{Cu}$ ions by dissolving $12.08 \mathrm{gm}$ of Cu nitrate in $1 \mathrm{~L}$ distilled water (via the above nitrogen purging) and $40.4 \mathrm{gm}$ of ferric nitrate in $1 \mathrm{~L}$ distilled water. The samples were synthesized as $\mathrm{Cu}_{0.5} \mathrm{M}$ and $\mathrm{CuM}$ samples for partial substitution (50 and $100 \%$ of ferrous ions). 


\subsection{Drug loading and release}

Ciprofloxacin was loaded on the fabricated NPs through physical hybridization (Mabrouk et al., 2019). For this objective, a normalized $(1 \% \mathrm{w} / \mathrm{v})$ solution of chitosan was utilized in which $10 \% \mathrm{w} / \mathrm{w}$ ciprofloxacin was dispersed. In the mixture, an appropriate amount of $\mathrm{M}$ or $\mathrm{Cu}_{0.5} \mathrm{M}$ or $\mathrm{CuM}$ powder was blended. The whole system was then dehydrated at $40^{\circ} \mathrm{C}$ for overnight $(20 \mathrm{~h})$. The same procedure was repeated with the above condition, except for the drug inclusion to evaluate the chitosan influence on the final features of the obtained MNPs. Ciprofloxacin release from the drug containing NPs were determined by immersing $200 \mathrm{mg}$ of the dried drug-loaded samples (containing $\sim 20 \mathrm{mg}$ of ciprofloxacin) in $50 \mathrm{~mL}$ of phosphate buffer solution (PBS) $\left(\mathrm{pH}=7.4\right.$ ) at $37^{\circ} \mathrm{C}$. At specific time intervals, $5 \mathrm{~mL}$ of the solution was withdrawn, and it was replaced with an equivalent volume of PBS. UV visible spectrophotometer (Jasco V-730) was used to determine the amount of released drug by monitoring the absorbance at the wavelength of $\lambda_{\max }=272 \mathrm{~nm}$. The ciprofloxacin loading and encapsulation efficiency were calculated according to the following equations.

$$
\begin{aligned}
& \% \text { Drug loading }=\frac{\text { Weight of drug in formulation }}{\text { Weight of total formulation }} \times 100 \\
& \% \text { Encapsulation Efficiency }=\frac{\text { Actual drug loading }}{\text { Theoretical drug loading }} \times 100
\end{aligned}
$$

\subsection{Physical characterization}

To identify the influence of $\mathrm{Cu}$ presence on the physical characteristics and to prove its inclusion into the developed MNPs, X-ray diffraction analysis (XRD, model BRUKER Axs, D8ADVANCE, Germany), was applied for each sample. The $2 \theta$ diffractogram curves were found in the range $2-$ $90^{\circ}$ and $2 \%$ min scan speed. As a reference for the identification of the designed phases, the report of the Joint Committee on Powder Diffraction Standard (JCPDS, 1970) was used.

\subsection{Chemical characterization}

The chemical interactions that take place upon the inclusion of $\mathrm{Cu}$ and after chitosan/ciprofloxacin hybridization were confirmed using Fourier transformer infrared (FTIR) spectrophotometer (model FT/IR-6100 type A, USA). Thin discs were prepared by mixing $\mathrm{KBr}$ with very small quantity of the sample by molding and compression. These discs were then scanned in range of $4000-400 \mathrm{~cm}^{-1}$.

\subsection{Morphology, size and elemental analysis}

Scanning electron microscopy coupled with energy-dispersive X-ray microanalysis, (SEM/EDXA model FEJ quanta 250 Fei-Holland) at $15 \mathrm{kVm}$, transmission electron microscope (TEM) were utilized to determine the influence of the inclusion of $\mathrm{Cu}$ and after chitosan/ciprofloxacin hybridization

\subsection{Magnetic properties}


Vibrating sample magnetometer (VSM) at room temperature was utilized to determine the influence of $\mathrm{Cu}$ ion concentration on the final magnetic feature of the MNPs. Specimens were put inside appropriately positioned detecting coils and were allowed to experience sinusoidal movement, i.e., precisely vibrated. The subsequent magnetic motion changes instigate a voltage in the detecting coils that is corresponding to the magnetic moment of the example.

\subsection{Antibacterial experiments}

Agar plug diffusion technique (Perez etal, 1999) was utilized to evaluate the in-vitro antibacterial activity of the prepared NPs. $0.1 \mathrm{ml}$ sample from an18 hr broth culture of the above-mentioned bacteria was adjusted to a turbidity equivalent of 0.5 McFarland standards (Zamora and PerezGracia, 2012). This was then administered into a sterile petri-dish named with the bacterial species. Molten sterile Muller-Hinton was used to aseptically fill the plates and delicately shake the microorganisms to disperse them homogeneously in the medium in the plate. The agar plates were allowed to solidify, after which the same weights of 15 powder samples were put as disks on the agar surfaces, then the plates were allowed to diffuse for $2 \mathrm{hr}$ at $4^{\circ} \mathrm{C}$. The experiment was conducted in triplicates. All plates were incubated at $37^{\circ} \mathrm{C}$ for 24 hours for bacterial strains and at $28-30^{\circ} \mathrm{C}$ for $48 \mathrm{hr}$ for fungal strain. Diameters of the cleared bacterial zones in the petri dishes were measured in millimeters (e.g., see Anitha and Muthukumaran, 2020).

\subsection{Drug release kinetics}

The kinetics of ciprofloxacin release mechanism were evaluated by using a mathematical model.Korsmeyer-Peppas model was utilized to regress the ciprofloxacin release kinetics from the tested MNPs and fit the obtained data. The general form of the model was selected as it was originally developed for drug release from NPs coated with polymer or its main component is polymeric particles of spherical shape in which the drug delivery is governed by polymer disintegration or diffusion of the drug (Korsmeyer et al., 1986). The Korsmeyer-Peppas model is given as follow:

$$
\mathrm{M}_{t} / \mathrm{M}_{\infty}=\mathrm{Kt}^{\mathrm{n}}
$$

where, $M_{t} / M_{\infty}$ is the fraction of drug released at time $t, K$ is the rate constant and, $n$ is a parameter defining the drug release mechanism. If the release profiles follow quasi-Fickian diffusion, the value of $n<0.5$, for Fickian diffusion $n=0.5$, and for non-Fickian or anomalous drug transport, $\mathrm{n}=0.5-1.0$. Therefore, a regression of the release data can provide an indication on the type of the release kinetics. 


\section{Results and discussion}

\subsection{Preparation of magnetite and $\mathrm{Cu}$ substituted samples}

The optimized co-precipitation method was utilized successfully to produce Cu-free and Cusubstituted MNPs. These nanoparticles were hybridized with chitosan/ciprofloxacin to develop multifunctional MNPs with impressive antibacterial activities and medication delivery vehicles as it will be discussed in the following sections.

\subsection{Crystallinity and phase formation of the prepared NPs}

To study and verify the crystalline patterns of the synthesized $\mathrm{Fe}_{3} \mathrm{O}_{4}$, X-ray powder diffraction analysis was carried out and the results are given in Figure 1.The effect of the substitution of ferrous by $\mathrm{Cu}$ ions, partially and completely, in magnetite sample (M)is represented by $\mathrm{Cu}_{0.5} \mathrm{M}$ and CuM, respectively, as shown in Figure 1a.
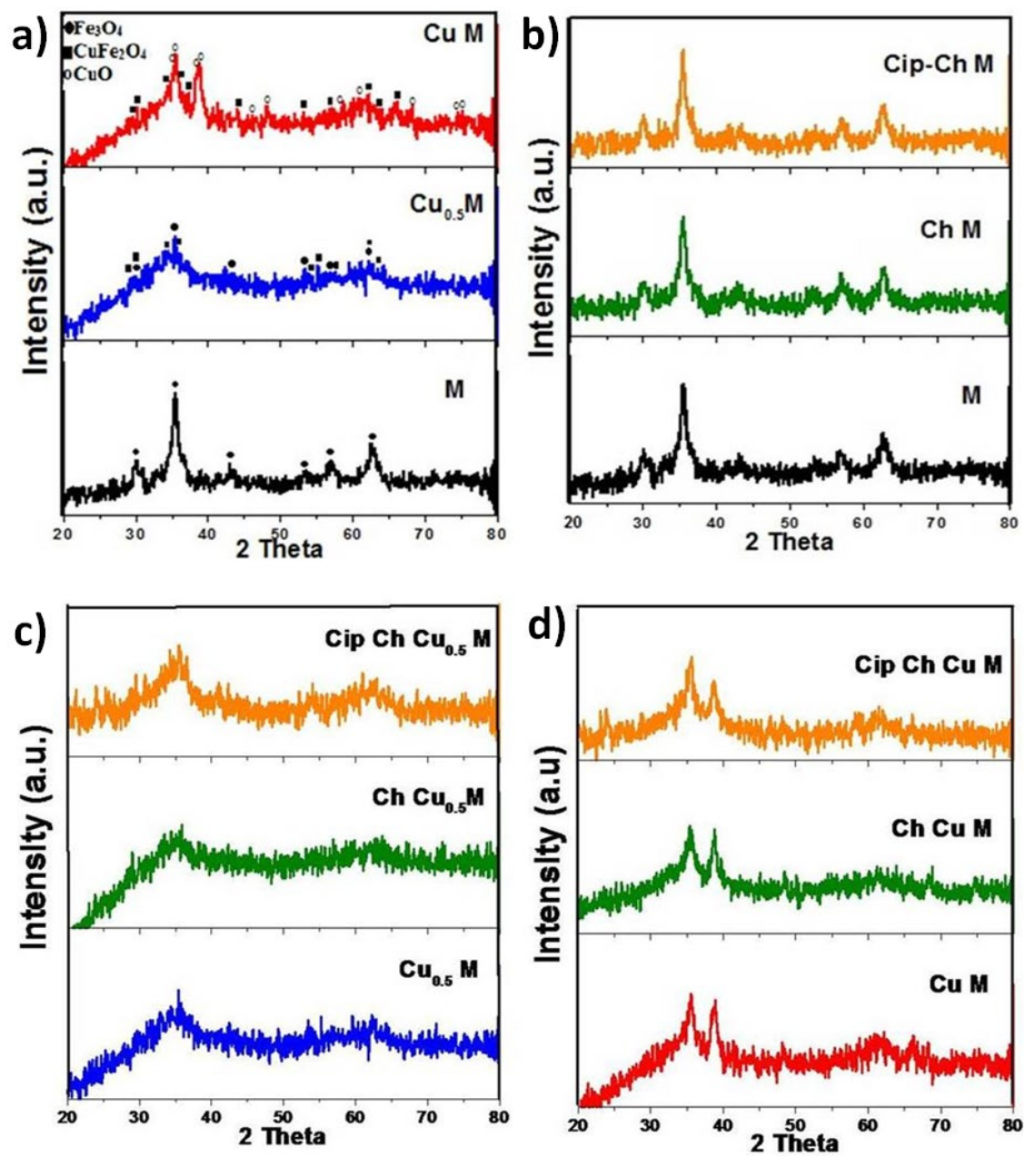

Figure 1 XRD patterns of a) magnetite $\mathrm{M}$, partial substitution of ferrous by copper $\mathrm{Cu}_{0.5} \mathrm{M}$, complete substitution of ferrous by copper CuM, b) Ch CuM and Cip-Ch CuM represent sample M with chitosan and chitosan-ciprofloxacin, respectively. c) $\mathrm{ChCu}_{0.5} \mathrm{M}$ and $\mathrm{Cip}-\mathrm{Ch} \mathrm{Cu}_{0.5} \mathrm{M}$ represent sample $\mathrm{Cu}_{0.5} \mathrm{M}$ with chitosan and chitosan- ciprofloxacin, respectively d) Ch CuM and Cip Ch CuM represent sample CuM with chitosan and chitosan-ciprofloxacin, respectively. 
It can be seen that the sample $M$ gives its patterns at $2 \theta=30.1^{\circ}, 35.4^{\circ} .43 .1^{\circ}, 53.4^{\circ}, 57^{\circ}$ and $62.6^{\circ}$, which are corresponding to standards peaks of $\mathrm{Fe}_{3} \mathrm{O}_{4}$ according to PDF 89-0691. Introducing $\mathrm{Cu}$, partially, into the structure produced compound with low crystallinity compared to the pure magnetite. The two phases $\mathrm{Fe}_{3} \mathrm{O}_{4}$ and $\mathrm{CuFe}_{2} \mathrm{O}_{4}$ were formed according to PDF 89-3854 and 340425 , respectively. However, the complete substitution of ferrous by $\mathrm{Cu}$ produced a semi crystalline mixture of $\mathrm{CuFe}_{2} \mathrm{O}_{4}$ and $\mathrm{CuO}$ according to PDF 89-0691 and 89-5899, respectively. $\mathrm{CuO}$ is the major phase in this sample. The presentation of $\mathrm{Cu}$ diminished the intensity of peaks for all Cu/MNPs samples may be because of its lower crystallinity or molecule size distinction (Pouran et al., 2016). From the past research (Abdellatif et al. 2017), it is evident that the metallic $\mathrm{Cu}$ ordinarily demonstrates a characteristic peak at 43.4, 50.5 and 74.2 2Ө. Moreover, the coating with chitosan or with ciprofloxacin did not change the patterns of the starting materials significantly (Figure 1b, $c$ and d). Table1 shows the crystallite size and the formed phases of the three samples $\mathrm{M}, \mathrm{Cu}_{0.5} \mathrm{M}$ and $\mathrm{CuM}$.

Table1. The crystallite size and the formed phases of the three samples $\mathrm{M}, \mathrm{Cu}_{0.5} \mathrm{M}$ and $\mathrm{CuM}$

\begin{tabular}{cccccc}
\hline Sample & $\mathbf{M}$ & \multicolumn{2}{c}{$\mathrm{Cu}_{0.5} \mathbf{M}$} & \multicolumn{2}{c}{ CuM } \\
\hline Phases & $\mathrm{Fe}_{3} \mathrm{O}_{4}$ & $\mathrm{Fe}_{3} \mathrm{O}_{4}$ & $\mathrm{CuFe}_{2} \mathrm{O}_{4}$ & $\mathrm{CuO}$ & $\mathrm{CuFe}_{2} \mathrm{O}_{4}$ \\
$\begin{array}{c}\text { Average crystallite } \\
\text { size(nm) }\end{array}$ & 10.4 & 22.5 & 25.3 & 14 & 27.8 \\
\hline
\end{tabular}

\subsection{Characterization of Chemical Composition}

From Figure 2, it can be seen that for the iron oxide (magnetite) possess only a major band at 560 $\mathrm{cm}^{-1}$. The intensity of this band decreases with increasing the substitution of ferrous by $\mathrm{Cu}$ ions with increase in the same time the bands at 1145 and $1632 \mathrm{~cm}^{-1}$, which related to the formation of $\mathrm{Cu}$ ferrite. These results were in line with the earlier report which detected FTIR bands for magnetite substituted with $\mathrm{Cu}$ (Masudi et al., 2020). The bands at 1482, 1388 and $1294 \mathrm{~cm}^{-1}$ are related to the coated layer of chitosan loaded ciprofloxacin on Cu-ferrite (Sanchayanukun and Muncharoen, 2020). 

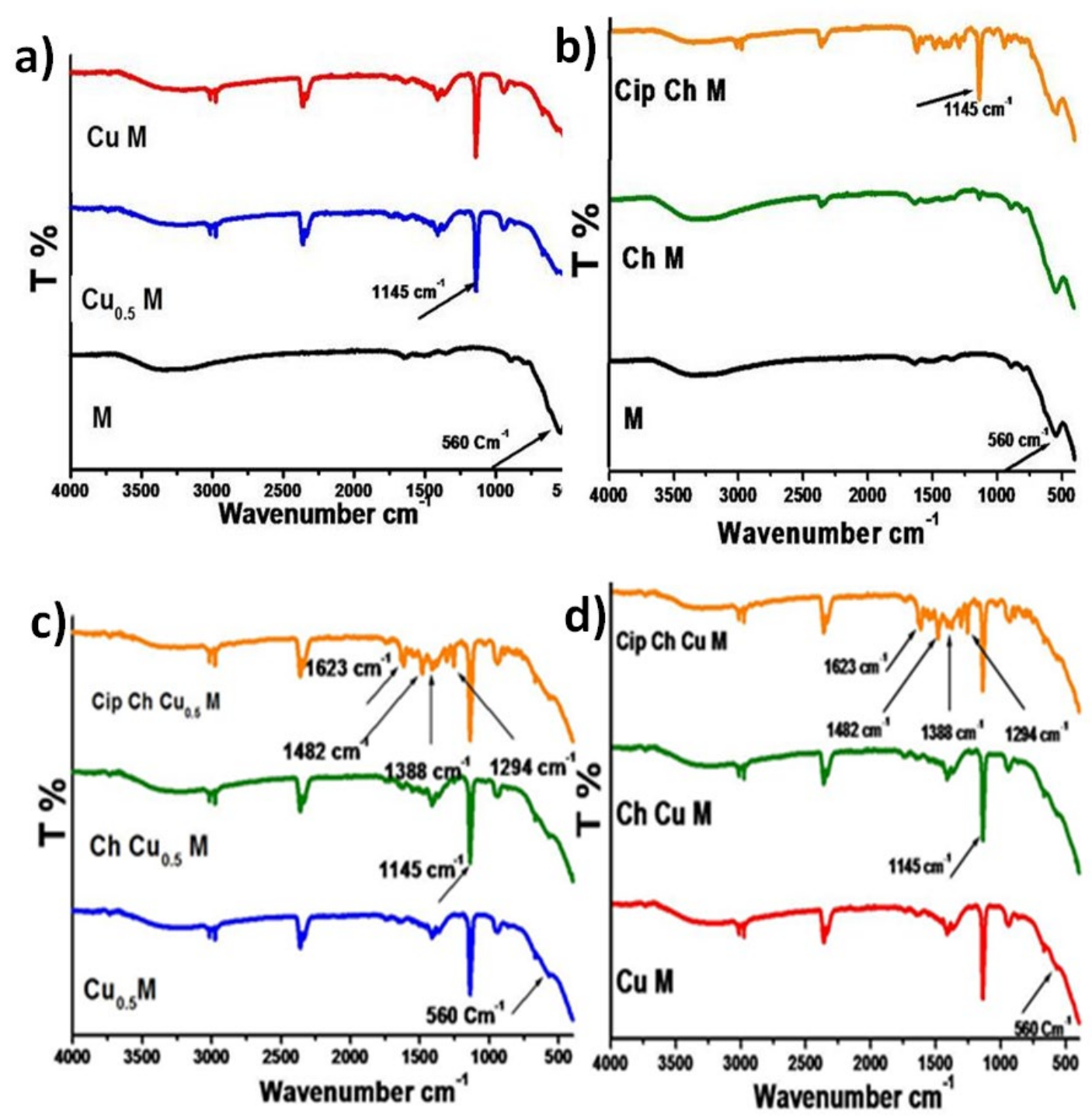

Figure 2 FTIR of a) magnetite $(M)$, partial substitution of ferrous by copper $\left(\mathrm{Cu}_{0.5} \mathrm{M}\right)$, complete substitution of ferrous by copper (CuM), b) ChCuM and Cip-ChCuM represent sample M with chitosan and chitosan-ciprofloxacin, respectively, c) $\mathrm{ChCu}_{0.5} \mathrm{M}$ and $\mathrm{Cip}-\mathrm{Ch} \mathrm{Cu}_{0.5} \mathrm{M}$ represent sample $\mathrm{Cu}_{0.5} \mathrm{M}$ with chitosan and chitosan-ciprofloxacin, respectively, d) ChCuM and CipChCuM represent sample CuM with chitosan and chitosan-ciprofloxacin, respectively.

\subsection{Characterization of NP Morphology}

The morphological properties of the samples $\mathrm{M}, \mathrm{Cu}_{0.5} \mathrm{M}$ and $\mathrm{CuM}$ and their modification by adding chitosan and ciprofloxacin are shown in Figure 3(a-i). The magnetite NPs are observed to contain agglomerated spherical particles which are similar in size as shown in Figure 3a. According to earlier research, magnetite particles of spherical shape are expected to occur owing to the dissolution-recrystallization phenomenon (Shahid and Choi, 2020, Jiang et al., 2020). The mechanism by which magnetite particles take the spherical structure is owed to an electrons exchange process that takes place between the ferric and ferrous ions during their interactions (Shahid and Choi, 2020). On the other hand, increasing the amount of $\mathrm{Cu}$ in samples, $\mathrm{Cu}_{0.5 \mathrm{M}}$ and CuM, strongly affects the morphology and particle size as shown in Figure 3(d and $\mathrm{g})$ as the 
particles lose its spherical shape and become harder (Emídio et al., 2020). Figure 3(b, e and h) shows that adding chitosan to $\mathrm{M}, \mathrm{Cu}_{0.5} \mathrm{M}$ and $\mathrm{CuM}$ samples helps in dissociation of the agglomerated particles which is greatly obvious in the sample Ch M (Figure 3b). Addition of ciprofloxacin to the previous samples, $\mathrm{ChM}, \mathrm{ChCu}_{0.5} \mathrm{M}$ and $\mathrm{ChCuM}$, increases again the connection between the particles in the shape of big granules as shown in Figure 3(c, $f$ and i). Earlier researchers introduced similar effect for the chitosan coating on magnetite NPs (Bezdorozhev et al., 2017, Morales et al., 2019, Sanchayanukun and Muncharoen 2020).
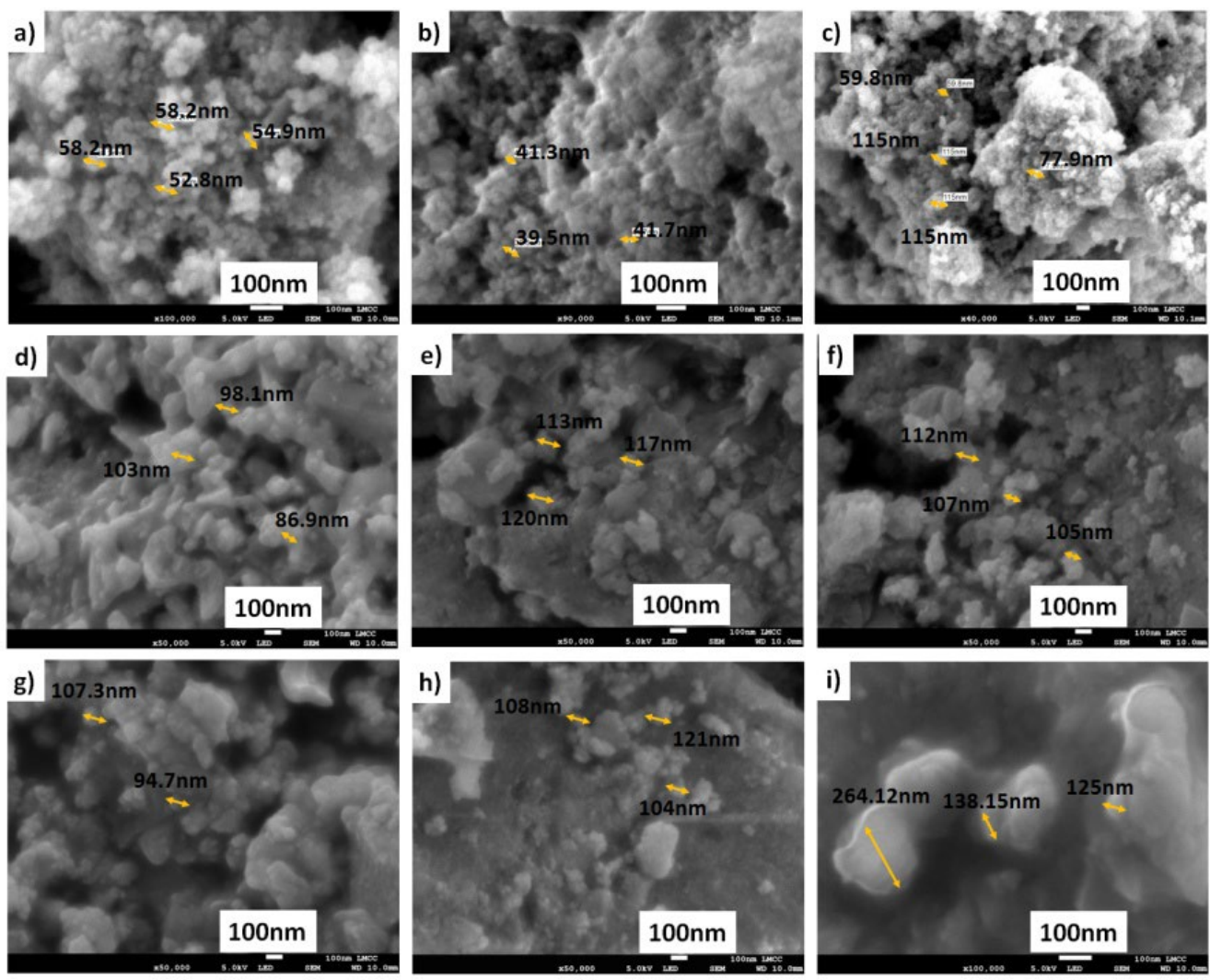

Figure 3 SEM images of a) magnetite, b) magnetite coated with chitosan and c) magnetite coated with chitosan loaded with ciprofloxacin drug; d) $\mathrm{Cu}_{0.5} \mathrm{M}$, e) $\mathrm{Cu}_{0.5} \mathrm{M}$ coated with chitosan and f) $\mathrm{Cu}_{0.5} \mathrm{M}$ coated with chitosan loaded with ciprofloxacin drug; g) CuM, h) CuM coated with chitosan and i) CuM coated with chitosan loaded with ciprofloxacin drug.

\subsection{Characterization of NP Structures (size)}

TEM images confirmed the nanostructures(size) of all prepared samples. Fine NPs were found with narrow particle size distribution. These results are in a good agreement with those obtained from XRD. The transition sample $\left(\mathrm{Cu}_{0.5} \mathrm{M}\right)$ between $\mathrm{M}$ and $\mathrm{CuM}$ has low crystallinity and smaller particle diameters. It was revealed early that magnetite NPs were synthesized through chemical precipitation technique, which produced NPs with diameters below $5 \mathrm{~nm}$ (Wu et al., 2008). These MNPs possess well-defined superparamagnetic performance and are most favorable for cells interlunations, which is useful for medication guided delivery. 

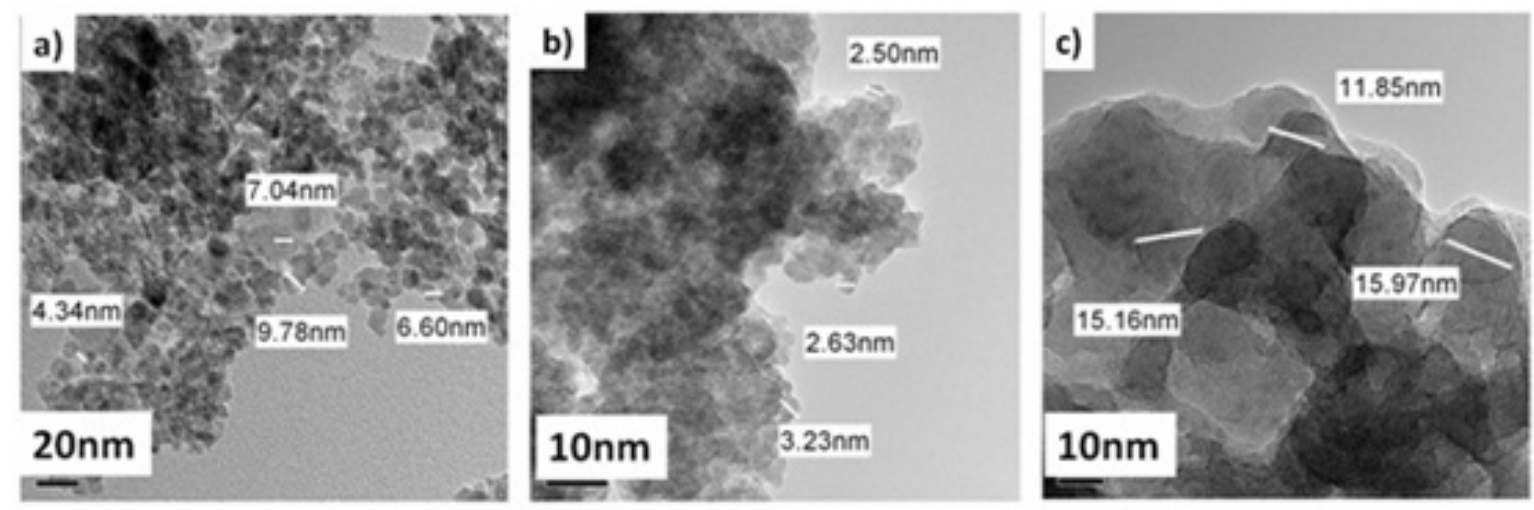

Figure 4 TEM images of a) $M$, b) $\mathrm{Cu}_{0.5} \mathrm{M}$ c) CuM

\subsection{Characterization of Elemental Mapping in NPs}

To identify the elemental distribution in the samples, EDAX mapping for $\mathrm{M}, \mathrm{Cu}_{0.5} \mathrm{M}$ and $\mathrm{CuM}$ samples was performed. The elemental analyses of the magnetite particles and sample $\mathrm{M}$ confirmed the basic constituents of the magnetite, i.e., oxygen and iron (Figure 5a). An increase in the intensity of $\mathrm{Cu}$ peaks from the sample $\mathrm{Cu}_{0.5} \mathrm{M}$ to the sample $\mathrm{CuM}$ was also observed due to an increasing amount of $\mathrm{Cu}$ in the sample (Figure $5(\mathrm{~b}, \mathrm{c})$ ). The degree of colors brightness is mostly the same in all the examined specimens, which indicates that the components of these MNPs are homogenously distributed in the specimens. These findings provide further confidence that a successful synthesis of the MNPs and the Cu substitutions using the facile chemical precipitation method have been achieved. It must be stated that the utilization of transitions metals such as $\mathrm{Cu}^{2+}, \mathrm{Ca}^{2+}$ and $\mathrm{Mg}^{2+}$ for biomedical application carries another concern into the picture, which is the harmfulness and the need to stay away from metal draining from the nanoconjugates (Colombo et al., 2012). Thus, an excellent elemental distribution and polymer coating procedure for the NPs ought to be considered as performed in the current study. This will ensure the adjusting of the leached inorganic part from developed MNPs to the encompassing media to expand their sustainability in biological conditions. 

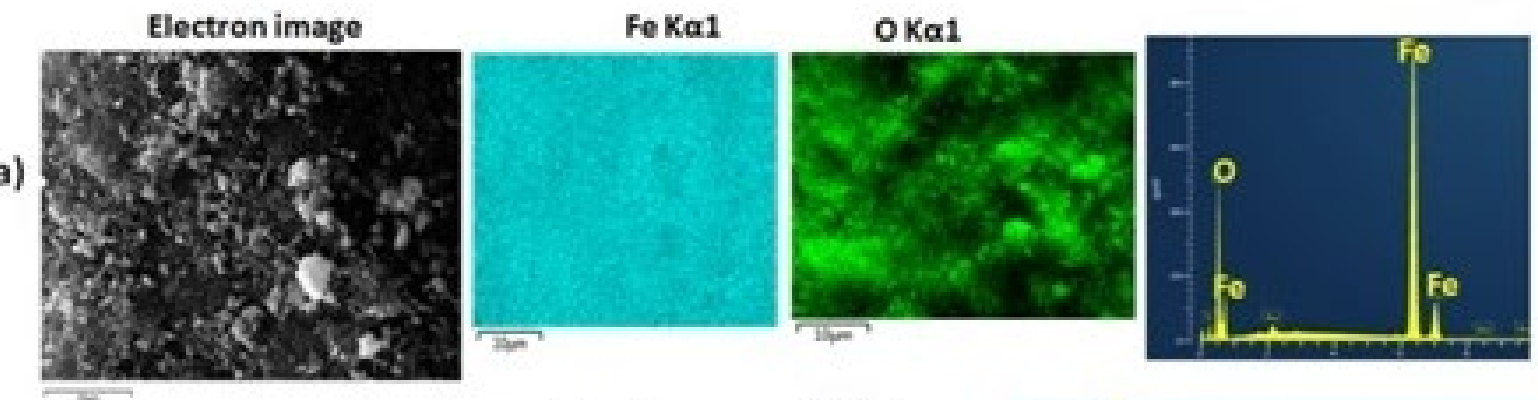

b)
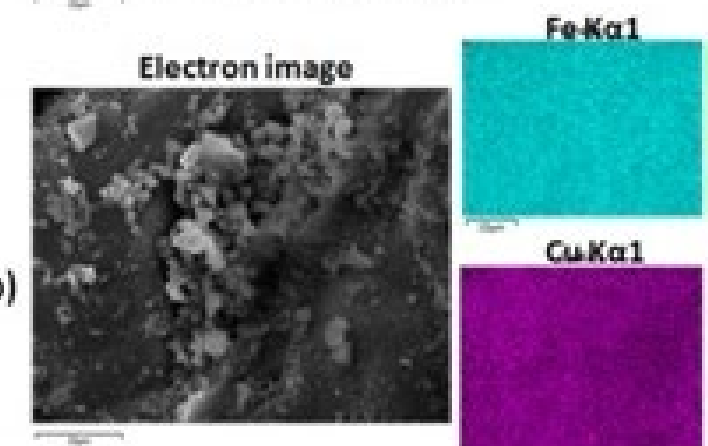

OKa1
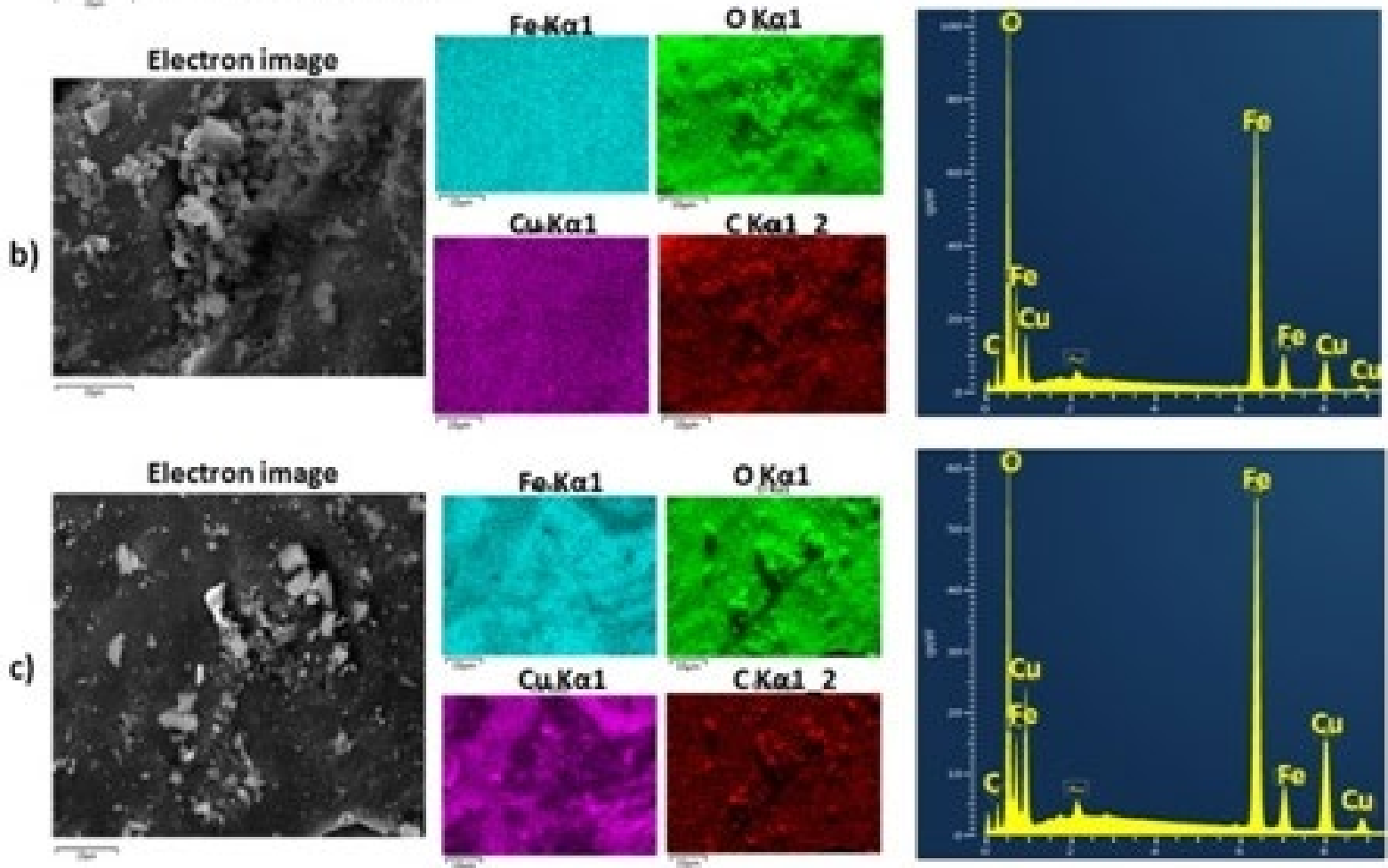

Figure 5 SEM images, elemental mapping and chart of a) $\mathrm{M}$, b) $\mathrm{Cu}_{0.5} \mathrm{M}$ and c) $\mathrm{CuM}$

\subsection{Characterization of NP magnetization}

Diminishing particles aggregation venture is an advantage that is possessed by MNPs characterized as superparamagnetic, in addition to maintaining magnetized upon removing the magnetic field. There are two reasons behind the great consideration of superparamagnetic NPs in biomedical applications, especially, in bioimaging and theranostics fields. The first reason is the very fine particle diameters that result in high surface-to-volume ratio. By this property the MNPs guarantee maximum drug/molecules loading and higher cell internalization. The second reason is the superparamagnetic feature that makes them externally controlled and directed to the specific diseased site (Rebolledo et al., 2008, Wang et al., 2010). 


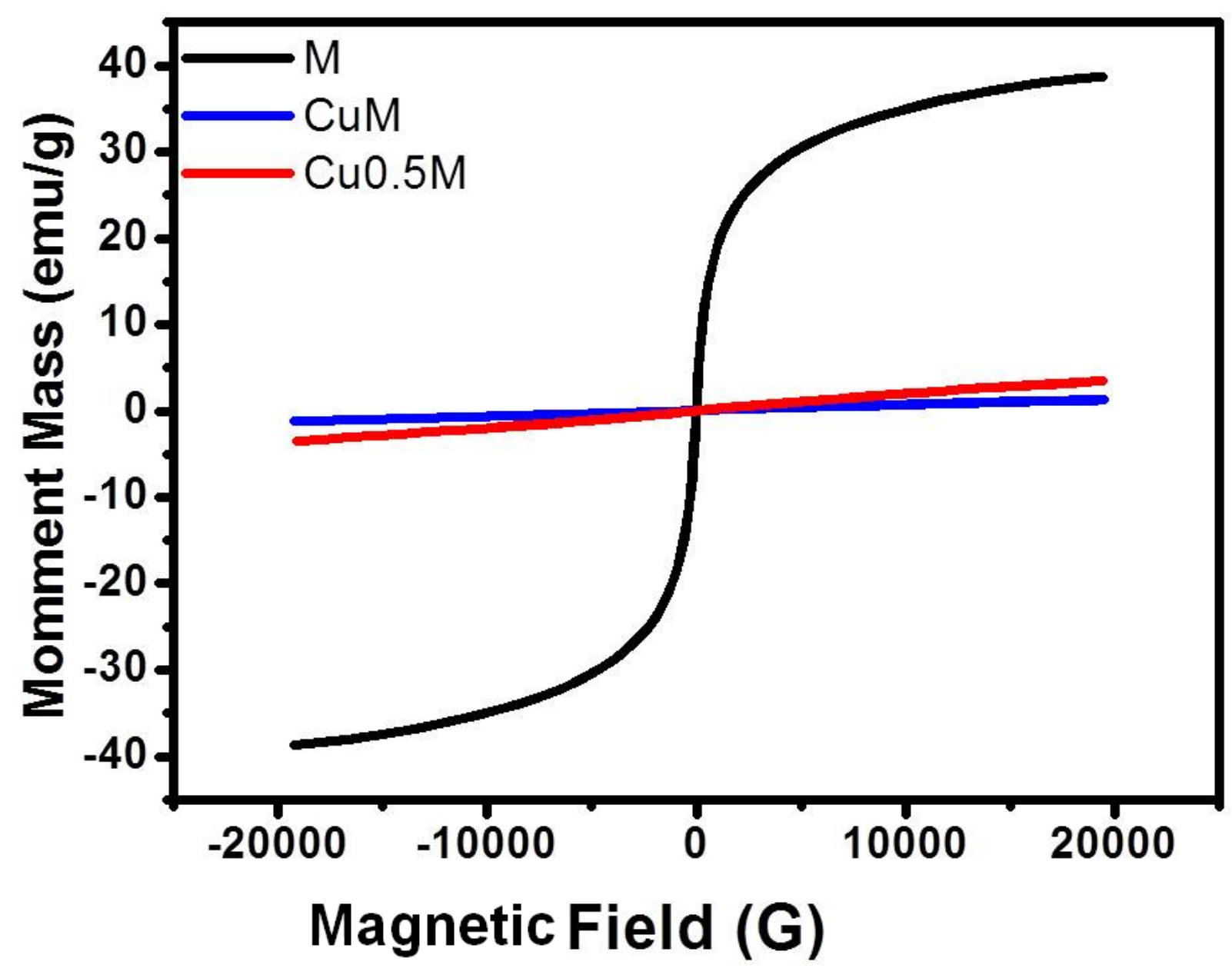

Figure 6 Magnetization hysteresis loops recorded for samples $\mathrm{M}, \mathrm{Cu}_{0.5} \mathrm{M}$ and $\mathrm{CuM}$ at room temperature

Figure 6 shows the measurements of the magnetic field-dependence of the magnetization of the particles of $\mathrm{M}, \mathrm{Cu}_{0.5} \mathrm{M}$ and $\mathrm{CuM}$ samples at room temperature. The saturation magnetization is determined around 38.7, 3.5 and $1.3 \mathrm{emu} / \mathrm{g}$ for samples $\mathrm{M}, \mathrm{Cu}_{0.5} \mathrm{M}$ and $\mathrm{CuM}$, respectively, which is smaller than previously reported value for bulk magnetite (92 emu/g). The magnetization value is directly related with the particle size and any increase in particle size may lead to higher magnetization value (Sharifi, et al., 2012, Shahid and Choi, 2020). The very low magnetization of sample CuM may be explained in terms of phase formation as the predominant phase is CuO. These features demonstrate that the synthesized magnetite in current research is a stable magnetic material at room temperature. However, sample M exhibits superparamagnetic behavior, owing to their relative moderate nanoscale (approximately $20 \mathrm{~nm}$ ), i.e., $\mathrm{Fe}_{3} \mathrm{O}_{4} \mathrm{NPs}$ can be in the superparamagnetic regime if the particle size is less than $20 \mathrm{~nm}$ (Sharifi, et al., 2012). This finding is in consistent with our TEM results. Magnetization decreases with the increase in $\mathrm{Cu}$ concentration for samples $\mathrm{Cu}_{0.5} \mathrm{M}$ and $\mathrm{CuM}$. 


\subsection{Antibacterial properties}

The bacterial activity of the prepared samples against Bacillus cereus, Escherichia coli and Candida albicans are showed in Figure 7. The results show that the highest bacterial activity was for CipChM sample against Escherichia coli. No bacterial activity was observed for ChM sample against the tested bacterial strains; however, pure magnetite was weakly sensitive towards Escherichia coli. The partial substitution of ferrous by $\mathrm{Cu}$ increases the inhibition zones from 0 to $12 \mathrm{~mm}$, from 12 to $33 \mathrm{~mm}$ and from 0 to $25 \mathrm{~mm}$ against Bacillus cereus, Escherichia coli and Candida albicans, respectively. When ferrous was completely substituted by $\mathrm{Cu}$, the inhibition zones reached to 26, 34 and 23mm against the Bacillus cereus, Escherichia coli and Candida albicans populations, respectively. The addition of chitosan to pure magnetite did not show any antibacterial influence on the strains. Other chitosan coated samples, $\mathrm{Ch} \mathrm{Cu}_{0.5} \mathrm{M}$ and $\mathrm{ChCuM}$ increased the inhibition rings against Bacillus cereus while decreased against Escherichia coli. Additionally, the antibacterial activity of the sample ChCu0.5M decreased against Candida albicans while increased with ChCuM sample. Generally, supplement the sample with ciprofloxacin drug had the most intense bacterial activity towards all the tested strains (Muthukumaran, 2020). Our samples were classified according to the strength of their bacterial activity (Table 2), and the antibiotics standards are summarized in Table 3. The inhibition zones of some samples were shown in Figure 8. Cu doped materials revealed similar results in early reported research (Anitha and Muthukumaran, 2020).

Table 2 Antibacterial activity strength of the tested samples against Bacillus cereus, Escherichia coli and Candida albicans

\begin{tabular}{llll}
\hline Sample name & \multicolumn{2}{c}{ Strength of antibacterial activity (diameter of inhibition zone, mm) } \\
\cline { 2 - 4 } & Bacillus cereus & Escherichia coli & Candida albicans \\
M & Resistant & Weakly sensitive (12) & Resistant \\
CipChM & Resistant & Resistant & Resistant \\
$\mathrm{Cu}_{0.5} \mathrm{M}$ & Strongly sensitive(43) & Strongly sensitive(48) & Moderately sensitive(27) \\
$\mathrm{ChCu}_{0.5} \mathrm{M}$ & Strongly sensitive(30) & Strongly sensitive(32) & Weakly sensitive(14) \\
CipChCu & Strongly sensitive(41) & Strongly sensitive(42) & Moderately sensitive(23) \\
CuM & Moderately sensitive(26) & Strongly sensitive(34) & Moderately sensitive(23) \\
ChCuM & Strongly sensitive(34) & Strongly sensitive(31) & Strongly sensitive(32) \\
CipCuM & Strongly sensitive(40) & Strongly sensitive(39) & Strongly sensitive(29) \\
\hline
\end{tabular}


Table 3. The antibacterial activity strength of the standards against Bacillus cereus, Escherichia coli and Candida albicans

\begin{tabular}{llll}
\hline Standards & \multicolumn{2}{c}{ Strength of antibacterial activity (diameter of inhibition zone, mm) } \\
\hline & Candida albicans & Escherichia coli & Bacillus cereus \\
TE 30 & Moderately sensitive(19) & Moderately sensitive(18) & Resistant \\
NV 30 & Moderately sensitive(20) & Weakly sensitive(16) & Resistant \\
CIT 5 & Resistant & Resistant & Weakly sensitive(13) \\
CH 50 & Resistant & Resistant & Strongly sensitive(32) \\
\hline
\end{tabular}

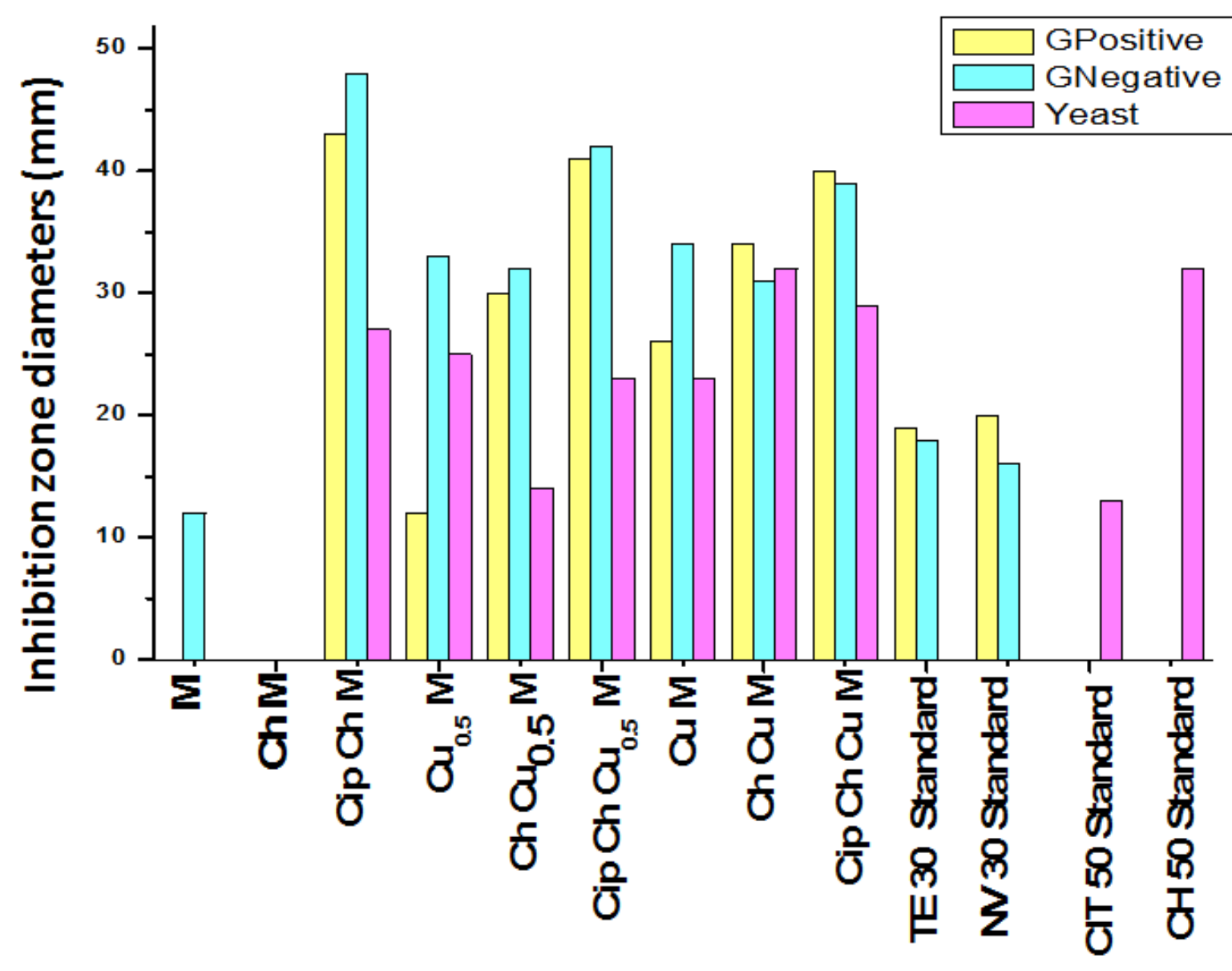

Figure 7. Antibacterial activity evaluations of different samples against Bacillus cereu (Grampositive bacteria), Escherichia coli (Gram-negative bacteria) and Candida albicans(yeast). 


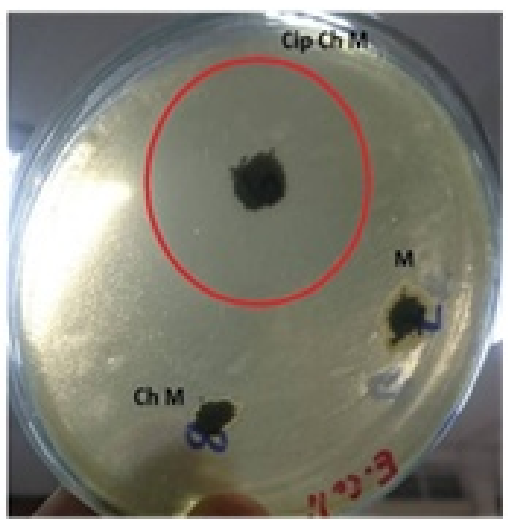

(a)

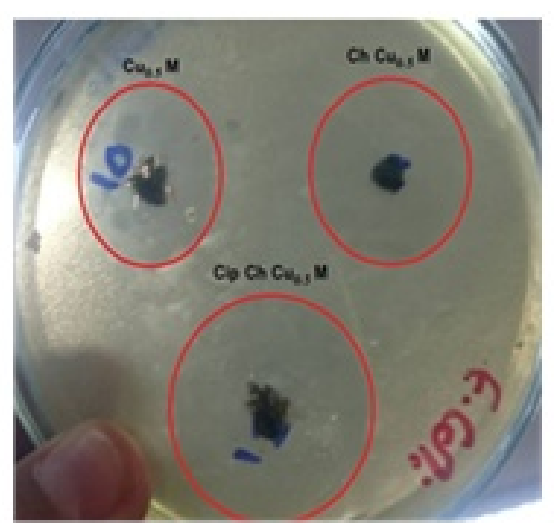

(b)

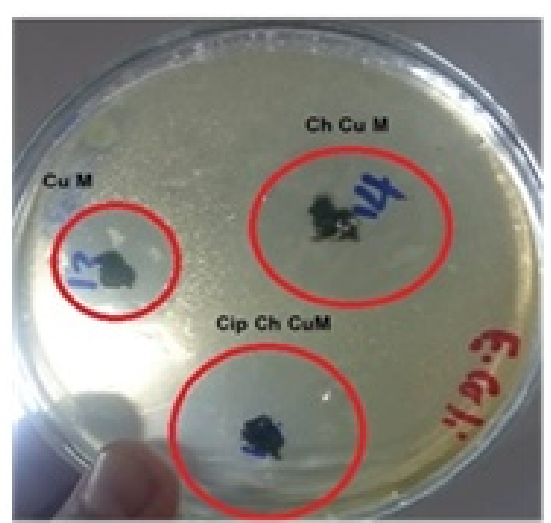

(c)

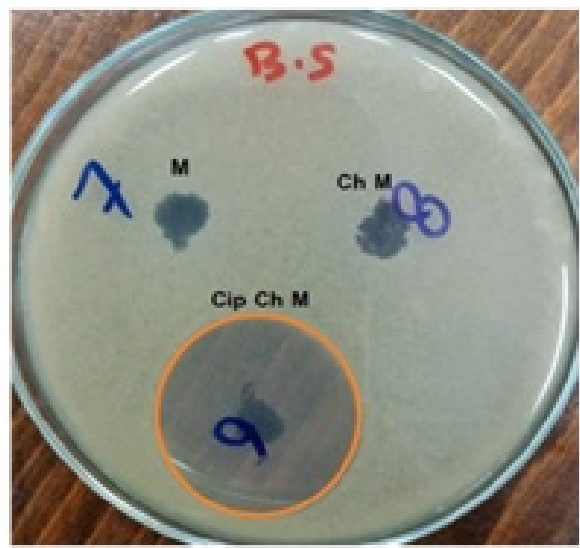

(d)

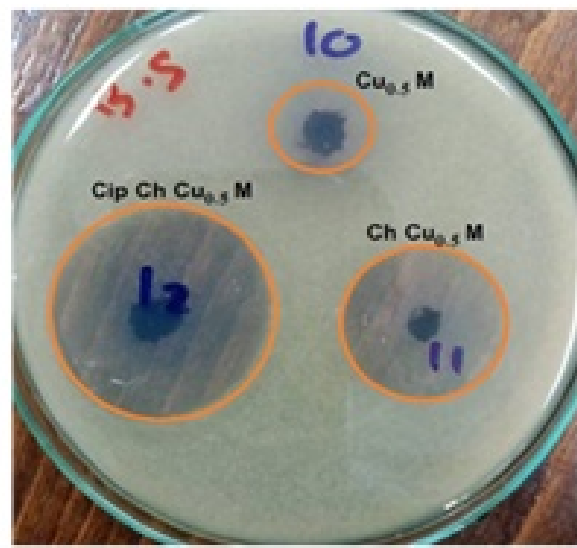

(e)

Figure 8 Inhibition zones of samples a) M, ChM and CipChM against Escherichia coli; b) $\mathrm{Cu}_{0.5} \mathrm{M}$, $\mathrm{ChCu}_{0.5} \mathrm{M}$ and $\mathrm{CipChCu}_{0.5} \mathrm{M}$ against Escherichia coli; c) CuM, ChCuM and CipChCuM against Escherichia coli; d) M, ChM and CipChM against Bacillus cereu; e) $\mathrm{Cu}_{0.5} \mathrm{M}$, $\mathrm{ChCu}_{0.5} \mathrm{M}$ and $\mathrm{CipCh}$ $\mathrm{Cu}_{0.5} \mathrm{M}$ against Bacillus cereu

\subsection{Drug release kinetics}

The ciprofloxacin release kinetics were studied to determine the performance of the prepared samples, namely, CipChM, CipChCu $\mathrm{Cu}_{0.5} \mathrm{M}$ and $\mathrm{CipChCuM,} \mathrm{on} \mathrm{the} \mathrm{drug} \mathrm{release} \mathrm{behavior.} \mathrm{The} \mathrm{drug}$ loading process was not followed up with any washing or purifications steps. Therefore, the ciprofloxacin loading efficiency in practice and theoretical calculated ones are similar in this work. As shown in Figure 9, a burst release of ciprofloxacin within the first $8 \mathrm{~h}$ was observed in CipChM sample. During this time, $\mathrm{CipChCu}_{0.5} \mathrm{M}$ and $\mathrm{CipChCuM}$ samples released a lower amount of ciprofloxacin. Introduction of $\mathrm{Cu}$ ion into the samples resulted in more efficient complexation process. During this time, $\mathrm{CipChCu}_{0.5} \mathrm{M}$ and $\mathrm{CipChCuM} \mathrm{samples} \mathrm{gave} \mathrm{convergent} \mathrm{lower} \mathrm{amounts}$ of released ciprofloxacin. The initial fast release of ciprofloxacin in CipChM sample may be attributed to the loss of cross linker. In addition, not all of the ciprofloxacin dispersed in chitosan solution is trapped inside the magnetite NPs, which result in quick release for weakly adsorbed ciprofloxacin on the magnetite. 
The above interpretation is consistent with the antibacterial result for the sample ChM which did not have any bacterial activity as the chitosan could not be found on the surface. As mentioned above, the release process was proceeded at a neutral solution of phosphate buffer solution adjusted $\mathrm{pH}$ 7.4. At this $\mathrm{pH}$, ciprofloxacin has the zwiterionic form due to the presence of carboxylic $\left(\mathrm{CO}_{2} \mathrm{H}\right)$ and secondary amine $\left(\mathrm{NH}_{2}{ }^{-}\right)$group (Paluch et al., 2013). In turn, the anionic groups of $\mathrm{CO}_{2} \mathrm{H}$ of ciprofloxacin react with the positively charged amine groups of chitosan to form complexes, which may be a reason for adsorption of ciprofloxacin on chitosan. On the other hand, amine groups of chitosan chelate with $\mathrm{Cu}$ ions. It was demonstrated that $\mathrm{Cu}$ considered as one of the most interacting metal with chitosan (Rhazi et al., 2002, Brunel et al., 2013). These reasons may explain the slow ciprofloxacin release for the samples $\mathrm{CipChCu}_{0.5} \mathrm{M}$ and $\mathrm{CipChCuM}$. After $8 \mathrm{~h}$, a sustained release of ciprofloxacin was observed from CipChM into the medium. However, a sustained and prolonged release of ciprofloxacin was achieved from $\mathrm{CipChCu}_{0.5} \mathrm{M}$ and $\mathrm{CipChCuM}$. Starting from $25 \mathrm{~h}$, the released ciprofloxacin from CipChCuM was noticed to be slightly higher than of $\mathrm{CipChCu}_{0.5} \mathrm{M}$. During a 30-day period, the total amounts of released drug from CipChM, CipChCu 0.5 M and CipChCuM were 85,26 , and $20 \%$, respectively.

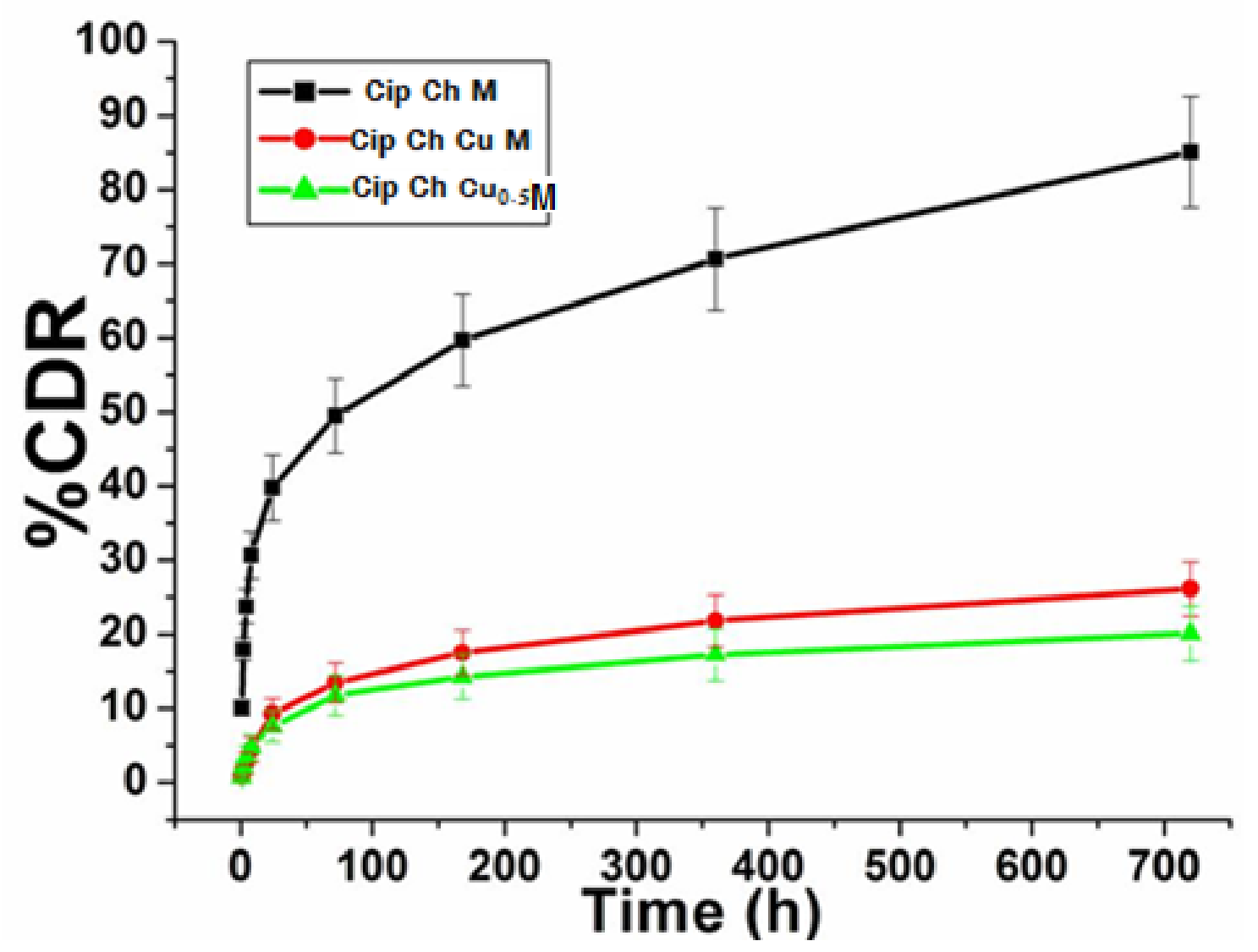

Figure 9 Ciprofloxacin release from CipChM, $\mathrm{CipChCu}_{0.5} \mathrm{M}$ and $\mathrm{CipChCuM}$ 


\subsection{Mechanism of ciprofloxacin release}

The obtained parameters after applying the above-mentioned rate expression for the ciprofloxacin release data from the fabricated MNPs are presented in Table 4. It was found that the ciprofloxacin release from the Cu-free and partial substituted followed the Ritger-Peppas models for nonswellable expanding framework. Based on the Korsmeyer-Peppas model fitting, for spherical particles a value $n>0.5$ is characteristic for Fickian diffusion. This implies that the medication discharge followed both controlled dissemination and disintegration mechanisms. Furthermore, the release from Cu-full substituted sample followed the non-Fickian diffusion model as affirmed by the $R^{2}$ esteems and $n<0.5$. Similar explanation was reported for mesoporous silica nanospheres coated with PEG polymers (Moodley and Singh, 2019). Thus, the medication moved from the magnetite surface into the encompassing PBS. These outcomes affirmed our thoughts that the discharge conduct and its mechanism were constrained by chitosan degradation, which is accompanied with ciprofloxacin release. However, a highly appropriate model could be a multifaceted model that incorporates the effects of ciprofloxacin diffusion co-efficient, electrostatic forces between ciprofloxacin and chitosan matrix, and the heterogenous structure of developed MNPs medication guided delivery system.

Table 4 Release kinetics parameters of different ciprofloxacin-loaded MNPs

\begin{tabular}{|c|c|c|c|c|c|c|c|c|}
\hline \multirow[t]{2}{*}{$\begin{array}{l}\text { Formula } \\
\text { code }\end{array}$} & \multicolumn{3}{|c|}{$\mathbf{R}^{2}$-value ${ }^{\dagger}$} & \multicolumn{2}{|c|}{$\begin{array}{l}\text { Korsmeyer-Peppas } \\
\text { model }\end{array}$} & \multirow[t]{2}{*}{$\mathrm{n}$} & \multirow[t]{2}{*}{$\mathbf{K}^{*}$} & \multirow[t]{2}{*}{$\begin{array}{l}\operatorname{RE}_{0-720 \mathrm{~h}^{\ddagger}} \\
(\%)\end{array}$} \\
\hline & $\begin{array}{l}\text { Zero- } \\
\text { order }\end{array}$ & $\begin{array}{l}\text { Fickian } \\
\text { diffusion }\end{array}$ & $\begin{array}{c}\text { Korsmeyer- } \\
\text { Peppas } \\
\text { model }\end{array}$ & $\begin{array}{c}t_{50}{ }^{* *} \\
\text { (hours) }\end{array}$ & $\begin{array}{c}\text { t90 }^{* * *} \\
\text { (hours) }\end{array}$ & & & \\
\hline CipCh M & 0.766 & 0.929 & 0.931 & 228.061 & 669.839 & 0.287 & 14.056 & 901.225 \\
\hline $\begin{array}{l}\text { CipCh } \\
\mathrm{Cu}_{0.5} \mathrm{M}\end{array}$ & 0.774 & 0.944 & 0.970 & 1308.511 & 2490.867 & 0.515 & 1.204 & 239.988 \\
\hline $\begin{array}{l}\text { CipCh } \\
\text { CuM }\end{array}$ & 0.741 & 0.924 & 0.916 & 1803.334 & 3418.88 & 0.452 & 1.387 & 203.5115 \\
\hline
\end{tabular}

$\mathrm{n}$ is the diffusion exponent,

${ }^{*} \mathrm{~K}$ is the release rate constant,

${ }^{* *} t_{50}$ is time required for $50 \%$ of the drug to be released

${ }^{* * *} t_{90}$ is time required for $90 \%$ drug release

${ }^{\ddagger} \mathrm{RE}{ }_{0-720 \mathrm{~h}}$ is the release efficiency of drug from 0 to 720 hours

${ }^{\dagger} R^{2}$-value is the value for regression co-efficient 


\section{Conclusion}

We have developed MNPs multi-functional systems through using facile chemical precipitation technique, free and substituted with $\mathrm{Cu}$. Partial and full substitution of $\mathrm{Cu}$ in magnetite structures was confirmed by FTIR and EDAX analyses. The morphology, particle diameters and magnetization of the fabricated MNPs were influenced by the presence and the concentration of $\mathrm{Cu}$ ions. These MNPs were tested for their magnetization, antibacterial activity and medication delivery rate as potential systems for selective treatments. It worthy to highlight, that the developed MNPs herein were proved to be good selective medication vehicles themselves, which could be adjusted by controlling the $\mathrm{Cu}$ substitution percentage and the polymer masking process. Moreover, the ciprofloxacin (antibiotic model drug) kinetics release from the developed MNPs was constrained by chitosan degradation, which is accompanied with ciprofloxacin release. These combined features of the developed MNPs promise their applications in drug delivery field after evaluating their in vivo metabolic forms and quantification of the dispersion of the MNPs in animal model.

\section{Acknowledgement}

The authors wish to communicate their gratefulness to the Academy of Medical Sciences, UK for providing a travelling fellowship to Dr Mostafa Mabrouk (first author) to Loughborough University, UK through the Academy's Daniel Turnberg UK/Middle East Travel Fellowship.

\section{References}

Abd El-Wahab R.M., El-Mekkawi D.M., Hassan S. A., Selim M.M, 2014. Single Step Solid Combustion Route for Preparing Nanosized NiO, Egypt. J. Chem. 57, 199 - 214.

Abdellatif M.H., Innocenti C., Liakos I., Scarpellini A., Marras S., Salerno M., 2017. Effect of JahnTeller distortion on the short-range magnetic order in copper ferrite, J. Magn. Magn Mater. 424, 402-409.

Ahmad T., Ramanujachary K., Lofland S.E, Ganguli A.K., 2006. Magnetic and electrochemical properties of nickel oxide nanoparticles obtained by the reverse-micellar route, Solid State Sciences, 8, 425.

Aisida S.O., Akpa P.A., Ahmad I., Zhao T-k., Maaza M., Ezema F.I., 2020. Bio-inspired encapsulation and functionalization of iron oxide nanoparticles for biomedical applications, European Polymer Journal, Volume 122, 109371 
Anitha S. and Muthukumaran S., 2020. Structural, optical and antibacterial investigation of La, Cu dual doped $\mathrm{ZnO}$ nanoparticles prepared by co-precipitation method, Materials Science and Engineering: C, 108,110387.

Arora V., Sood A., Shah J., Kotnala R.K., Jain T. K., 2017. Synthesis and characterization of pectin-6-aminohexanoic acid-magnetite nanoparticles for drug delivery Materials Science and Engineering C 80, 243-251.

Bezdorozhev O., Kolodiazhnyi T., Vasylkiv O., 2017. Precipitation synthesis and magnetic properties of self-assembled magnetite-chitosan nanostructures, Journal of Magnetism and Magnetic Materials, Volume 428, 406-411.

Brunel F., EIGueddari N.E., Moerschbacher B.M., 2013.Complexation of copper(II) with chitosan nanogels: Toward control of microbial growth, Carbohydrate Polymers, 92, 1348- 1356.

Chiu C-Y, Yen T-E, Liu S-H, Chiang M-T, 2020. Comparative Effects and Mechanisms of Chitosan and Its Derivatives on Hypercholesterolemia in High-Fat Diet-Fed Rats, Int. J. Mol. Sci. 2020, 21, 92; doi:10.3390/ijms21010092.

Colombo M., Carregal-Romero S., Casula M.F., Gutiérrez L., Morales M.P., Böhm I.B., Heverhagen J.T., Prosperi D., Parak W.J., 2012. Biological applications of magnetic nanoparticles, Chem. Soc. Rev. 41, 4306.

Cruz I. F., Freire C., Araújo J.P., Pereira C., Pereira A.M., 2018. Chapter 3 - Multifunctional Ferrite Nanoparticles: From Current Trends Toward the Future, Editor(s): Ahmed A. El-Gendy, José M. Barandiarán, Ravi L. Hadimani, In Micro and Nano Technologies, Magnetic Nanostructured Materials, Elsevier, Pages 59-116.

Dierstein A., Natter H., Meyer F., 2001. H.-O Stephan, Ch Kropf, R. Hempelmann,. Electrochemical deposition under oxidizing conditions (EDOC): A new synthesis for nanocrystalline metal oxides. ScriptaMaterialia. 44, 2209-2212. DOI: 10.1016/S1359-6462(01)00906-X.

El-Sayed S.A.M., Mabrouk M., Khallaf M. E., Abd El-Hady B. M., El-Meliegy E., Shehata M.R., 2020. Antibacterial, drug delivery, and osteoinduction abilities of bioglass/chitosan scaffolds for dental applications, Journal of Drug Delivery Science and Technology, 57, 101757. 
Emídio E.S., Hammer P., Pupo Nogueira R.F.,2020. Simultaneous degradation of the anticancer drugs 5-fluorouracil and cyclophosphamide using a heterogeneous photo-Fenton process based on copper-containing magnetites (Fe3-xCuxO4), Chemosphere, 241, 124990.

Han D.Y., Yang H.Y., Shen C.B., 2004. Synthesis and size control of NiO nanoparticles by waterin-oil microemulsion. Power Technology 147, 113.

Hosu O, Tertis M, and Cristea C., 2019. Implication of Magnetic Nanoparticles in Cancer Detection, Screening and Treatment, Magnetochemistry 5, 55; doi:10.3390/magnetochemistry5040055

Jiang C., Wang B., Wu Z., Qiu J., Ding Z., Zou J., Chen S., Gao P., Niu X., Wang L., Li H., 2020. Electrolyte-assisted dissolution-recrystallization mechanism towards high energy density and power density CF cathodes in potassium cell, Nano Energy, 70, 104552.

Joint Committee on Powder Diffraction Standards, Anal. Chem. 42 (11) (1970), 81A-A.

Justin P., Meher S.K., Rao G.R., 2010.Tuning of Capacitance Behavior of NiO Using Anionic, Cationic, and Nonionic Surfactants by Hydrothermal Synthesis, Journal of Physical Chemistry C $114,5203$.

Karthik K., Selvan G.K, Kanagaraj M., Arumugam S.,Jaya N.V., 2011. Particle size effect on the magnetic properties of $\mathrm{NiO}$ nanoparticles prepared by a precipitation method Journal of Alloys and Compounds 509, 181.

Korsmeyer R.W., Lustig S.R., Peppas N.A., 1986. Solute and penetrant di_usion in swellable polymers. I. Mathematical modeling. J. Polym. Sci. Part B Polym. Phys., 24, 395-408.

Korzeniowska A., Strzempek W., Makowski W., Menaszek E., Rotha W. J., Gil B., 2020. Incorporation and release of a model drug, ciprofloxacin, from non-modified SBA-15 molecular sieves with different pore sizes, Microporous and Mesoporous Materials 294, 109903.

Liu H., Wang C., Li C., Qin Y., Wang Z., Yang F., Li Z., Wang J., 2018. A functional chitosan-based hydrogel as a wound dressing and drug delivery system in the treatment of wound healing, RSC Adv., 8, 7533.

Mabrouk M., Kenawy S. H., El-Bassyouni G.T., Soliman A.AF. and Hamzawy E. M.A., 2019. Cancer cells treated by clusters of copper oxide doped calcium silicate, Adv Pharm Bull, 9(1), 102109. 
Mahdavinia G.R., Karimi M. H., Soltaniniya M., Massoumi B., 2019. In vitro evaluation of sustained ciprofloxacin release from K-carrageenan-crosslinked chitosan/hydroxyapatite hydrogel nanocomposites, International Journal of Biological Macromolecules 126, 443-453.

Masudi A., Jusoh N.W.C., Jusoh R., Jaafar N.F., Jalil A.A., Firdausi A., Hartanto D.,2020. Equidistant crystal distortion arrangement of copper doped magnetite for paracetamol degradation and optimization with response surface methodology (RSM), Materials Chemistry and Physics, 250, 122995.

Moodley T. and Singh M., 2019. Polymeric Mesoporous Silica Nanoparticles for Enhanced Delivery of 5- Fluorouracil In Vitro, Pharmaceutics 11, 288; doi:10.3390/pharmaceutics11060288

Morales F., Márquez G., Sagredo V., Torres T.E., Denardin J.C., 2019. Structural and magnetic properties of silica-coated magnetite nanoaggregates, Physica B: Condensed Matter 572, 214 219.

Paluch K.J., McCabe T., Müller-Bunz H., Corrigan O.I., Healy A.M., Tajber L. 2013. Formation and physicochemical properties of crystalline and amorphous salts with different stoichiometries formed between ciprofloxacin and succinic acid, Mol. Pharmaceutics 10 (10), 3640-3654.

Perez, C., Paul, M., Bazerque, P. 1990. An Antibiotic assay by the agar well diffusion method. Acta. Bio. Med. Exp. 15, 113-115.

Pham X.N., Nguyen T. P., Pham T. N., Tran T. T. N., Tran T.V. T., 2016. Synthesis and characterization of chitosan-coated magnetite nanoparticles and their application in curcumin drug delivery, Adv. Nat. Sci.: Nanosci. Nanotechnol. 7, 045010 (9pp).

Piñeiro Y., Gómez M. G., Alves L. de C., et al., 2020. Review, Hybrid Nanostructured Magnetite Nanoparticles: From Bio-Detection and Theragnostics to Regenerative Medicine, Magnetochemistry 6, 4; doi:10.3390/magnetochemistry6010004.

Pouran S.R., Bayrami A., Abdul Aziz A.R., Wan Daud W.M.A., Shafeeyan M.S., 2016. Ultrasound and UV assisted Fenton treatment of recalcitrant wastewaters using transition metal-substitutedmagnetite nanoparticles, J. Mol. Liq. 222, 1076-1084. 
Rebolledo A.F., Bomatí-Miguel O., Marco J.F., Tartaj P., 2008. A facile synthetic route for the preparation of superparamagnetic iron oxide nanorods and nanorices with tunable surface functionality, Adv. Mater. 20, 1760-1765.

Rhazi M., Desbrieres J., A. Rinaudo T. M., Vottero P., Alagui A., 2002.contribution to the study of the complxation of copper by chitosan and oligomers. Polymer, 43, 1267-1276.

Rodrigues G.R., López-Abarrategui C., de la Serna Gómez I., et al., 2019. Antimicrobial magnetic nanoparticles based-therapies for controlling infectious diseases, Int. J. Pharm., 555, 356-367.

Sanchayanukun P. and Muncharoen S.,2020. Chitosan coated magnetite nanoparticle as a working electrode for determination of $\mathrm{Cr}(\mathrm{VI})$ using square wave adsorptive cathodic stripping voltammetry, Talanta, 217, 21027,

Shahid M.K. and Choi Y.,2020.Characterization and application of magnetite Particles, synthesized by reverse coprecipitation method in open air from mill scale, Journal of Magnetism and Magnetic Materials 495, 165823.

Sharifi I., Shokrollahi H., Amiri S., 2012. Ferrite-based magnetic nanofluids used in hyperthermia applications, Journal of Magnetism and Magnetic Materials 324, 903-915.

Slavin Y.N., Asnis J., Häfeli U.O., et al., 2017. Metal nanoparticles: understanding the mechanisms behind antibacterial activity', J. Nanobiotechnol., 15, (1), 65.

Spirou S. V., Basini M., Lascialfari A., Sangregorio C, Innocenti C., 2018. Magnetic Hyperthermia and Radiation Therapy: Radiobiological Principles and Current Practice, Nanomaterials 8, 401; doi:10.3390/nano8060401

Spulber R., Chifiriuc C., Fleancu M., Popa O., Băbeanu N., 2018. antibacterial activity of magnetite nanoparticles coated with bee pollen extracts, DOI: 10.2478/alife-2018-0091.

Srivastava M., Chaubey S., Ojha A.K, 2009. Investigation on size dependent structural and magnetic behavior of nickel ferrite nanoparticles prepared by sol-gel and hydrothermal methodsMaterials Chemistry and Physics 118, 174.

Suk J.S., Xu Q., Kim N., et al., 2016. PEGylation as a strategy for improving nanoparticle-based drug and gene delivery. Adv. Drug Deliv. Rev. 99, 28-51. 
Turner R. J., 2020. Metal-based antimicrobial strategies, doi:10.1111/1751-7915.12785.

Urquijo J.P., Casanova H., Garces J., Morales A.L., 2011. Synthesis of magnetic nanoparticles: effects of polyelectrolyte concentration and $\mathrm{pH}$, Hyperfine Interact. 203,8591.http://dx.doi.org/10.1007/s10751-011-0369-6.

Wang H., Sun Y.-B., Chen Q.-W., Yu Y.-F., Cheng K., 2010. Synthesis of carbon-encapsulated superparamagnetic colloidal nanoparticles with magnetic-responsive photonic crystal property, Dalt. Trans. 39, 9565.

Wang W., Itoh Y, Lenggoro I.W., Okuyama K., 2004.Nickel and nickel oxide nanoparticles prepared from nickel nitrate hexahydrate by a low pressure spray pyrolysis, Materials Science and Engineering: B 111, 69.

Wang W.Z., Liu Y.K., Xu C.K, 2002Synthesis of NiO nanorods by a novel simple precursor thermal decomposition approach Chemical Physics Letters 362, 119.

Wang Y.G., Xia Y.Y., 2006.Electrochemical capacitance characterization of $\mathrm{NiO}$ with ordered mesoporous structure synthesized by template SBA-15, Electrochimica Acta 51, 3223.

Wu J.H., Ko S.P., Liu H.L., Jung M-H, Lee J.H., Ju J-S, Kim Y. K., 2008. Sub 5nm $\mathrm{Fe}_{3} \mathrm{O}_{4}$ nanocrystals via coprecipitation method, Colloids and Surfaces A: Physicochemical and Engineering Aspects, 313-314, 268-272.

Yang H.-W., Hua M.-Y., Liu H.-L., Huang C.-Y., Wei K.-C., 2012. Potential of magnetic nanoparticlesfor targeted drug delivery, Nanotechnol. Sci. Appl. 5, 73-86, http://dx.doi.org/10.2147/NSA.S35506.

Yu M.K., Park J., Jon S., 2012.Targeting Strategies for Multifunctional Nanoparticles in Cancer Imaging and Therapy, http://dx.doi.org/10.7150/thno.3463.

Zamora L.L. and Perez-Gracia M.T., 2012. Using digital photography to implement the McFarland method. J. R. Soc. Interface. 9,1892-1897. 